\title{
Opinion paper: Food loss and waste to animal feed
}

\author{
H. P. S. Makkar ${ }^{\dagger}$ \\ Food and Agriculture Organization of the United Nations (FAO), Animal Production and Health Division, 00153 Rome, Italy
}

(First published online 12 April 2017)

\section{Introduction}

Approximately 1.3 to $1.6 \mathrm{G}$ tonnes of food get wasted globally every year, which have enormous environmental, social and economic costs (see the Supplementary Material for details). Also the food loss and waste (FLW) has an impact on food security and on local and national economies. Similarly a large amount of non-food parts of crops (NFPC) such as crop residues and agro-industrial by-products originate from the food supply chain, which also require natural resources to produce and have economic and environmental costs associated with them. The nutrients in FLW and NFPC could be brought back to food chain by using them as a part of animal feed.

FAO organized an electronic conference on 'Utilization of food loss and waste as well as non-food parts as livestock feed' (Food and Agriculture Organization (FAO), 2015). The aims of this conference and approach used are available in the Supplementary Material to this paper. This paper discusses the limits of the FAO's (2015) version of the 'Definitional framework of food loss' in context to use of food items as animal feed, and amendments required; conversion of natural calamities led FLW to animal feed; and future research issues. According to previous definition of food waste: 'any losses in the foods intended for human consumption, if used as animal feed are considered as food loss', which, following the electronic conference, has been revised. Estimation of FLW, taking the revised definition, would present food loss that does not take into account the food consumed by animals to produce another food. The opinions expressed here may shape future R\&D work for converting FLW and NFPC to animal feed.

\section{Limits of the current food loss and waste definition}

A common understanding of the FLW in context to food use for animal feeding is a prerequisite for developing a simple but robust methodology for FLW estimation. Before the e-conference, the FAO 'Definitional framework of food loss'

\footnotetext{
${ }^{\dagger}$ E-mail: Harinder.Makkar@fao.org
}

defined redirection of food to animal feed and utilization of by-products or secondary products in principle meant for human consumption as FLW (Food and Agriculture Organization, 2014). Also according to this framework 'any losses in the foods such as grains, pulses, root crops, etc. "intended" for human consumption, if used as animal feed are considered as food loss'.

In the EU, 53\% of cereals grown are fed to farm animals. Cereals grown in the EU are rarely planted for an 'exclusive' feed use but a significant volume of cereals in Europe is indeed specifically grown for food use under 'Identity Preserved' growing programmes and contracts. In the United States of America maize and wheat are planted with the understanding that the resulting grain may go to either food or feed uses. Even if crops are exclusively grown for food, a part of which is also later used for feeding livestock. Reasons for the change of direction of use (the amount not known) include harvest failures, overproduction mainly of fruit and vegetables, poor quality for human use and grading for quality including the separation of broken rice for feed and market forces, among others. Sometimes the harvest is in excess for human use and the surplus production used for animal rations. Also food grains that do not pass the standards for human food production are sold to animal feed producers or traders of raw materials. Planning crop production for both food and feed is a common feature of farmers in integrated crop-livestock systems, whereby both the by-products and parts of the main product are allocated to animal feeding. Farmers may intentionally redirect food originally intended for human consumption to animal feed depending on prevailing circumstances if this results in higher returns and income either by selling or using it for their own livestock. Redirection may also be done for pastoralists to protect their livestock from winter hazards. A business-oriented farmer who intends to produce maize for human consumption will not sell if prices are low but will sell for poultry feed production if this offers better price. Accordingly a definition of FLW based on intention and not on the final product for human consumption seems unrealistic and the manner and type in which a product is to be used should not only reside with its designer or producer as 
both users and consumers continue to adapt product to suit their specific needs.

The main purpose of animal feed used for food-producing animals is to produce food of animal origin for human consumption; feed is therefore integral part of the food chain and cannot be considered as food loss. Only the part of food production which leaves the food supply chain for various reasons (pre- and post-harvest losses) may be referred to as food loss. The food eaten by humans and feed eaten by food-producing animals are seen as one from a food supply chain perspective.

There is a need to have a holistic all-inclusive definition of FLW, accommodating both humans and animals; and according to which if a food destined to feed humans is diverted to animal feeding, then such food is not truly lost, but transformed or recycled. The definitions and terms should facilitate accurate but at the same time simple calculations of food losses and waste including 'transformation'. As at the time of cultivation of food crops, intended purpose of its use as food or feed is generally not known, the designation of the diversion of food item to feed as food waste and loss is inappropriate. For accounting purposes, loss of food grains may be considered as food loss or waste till the time the decision is made to use food grains as animal feed; thereafter it is feed loss.

\section{Amendment to the definition of food loss and waste}

Based on the above arguments, a change of the definitions in the FAO 'Definitional framework of food loss' was needed. If a food destined to feed humans is diverted (through various circumstances) to animal feeding, then such food is not truly lost, but transformed or recycled.

Keeping in view the discussions held at the e-conference (FAO, 2015), the FAO 'Definitional framework of food loss and waste' has been revised; and the current version (October 2016), in context to the food use as animal feed, reads: 'If food products from the production to retail segments of the food supply chain are still fit for human consumption and nevertheless redirected to animal feed, it is a change in in-tended purpose and thus not food waste. Examples: a farmer grows maize for human food, but the buyer decides to sell the maize as chicken feed. A retailer selects odd-sized fruits and sells them as pig feed'. The FAO 'Definitional framework of food loss and waste' is evolving and we might see some more changes in the future.

The intention of food (and whether it can be considered a food waste or not) can differ depending on geographical and cultural factors. The FLW challenge in the developed world is a lot more consumer focused (more waste than loss) than in developing countries (more loss than waste). In the developed world all resources that entered the food supply chain and are maintained in the food supply chain by using as feed for food-producing animals, can effectively not be food waste. However in the developing world the food losses due to cultural practices and lack of infrastructure offer many more opportunities to convert them to 'worth' in the form of animal feed. An example being huge vegetable and fruit wastes that are left from whole-sale fruit and vegetable markets in the evenings in developing countries. These wastes are not decomposed and can be converted to animal feed. A study conducted by Bangladesh Livestock Research Institute (BLRI), jointly with FAO, has shown that daily vegetable wastes in sub-urban areas around Dhaka is substantial ( $0.3 \%$ of the traded vegetables), and the laboratory and feeding studies have shown that it is a good feed and can replace a part of the concentrates (generally expensive part of animal diet) in the livestock diets (Khan et al., 2016).

The levels of heavy metals, mycotoxins and pesticide residues in these wastes were below the levels that could adversely affect animal or human health. The study has also developed a processing technique for enhancing shelf life of these wastes (Khan et al., 2016). On the other hand, use of animal source food as animal feed may be illegal in many parts of the world due to the possibility of transmit diseases like foot-and mouth disease, African swine fever and Transmissible spongiform encephalopathies. South Korea and Japan both recycle ca. $40 \%$ of their food waste as animal feed, which is made possible by regulation of food waste collection, transport, storage, heat treatment and feed manufacture (zu Ermgassen et al., 2016). From a safety perspective it is critical that the feed chain is not used as a means to dispose of degraded or contaminated foodstuffs. The World Organisation for Animal Health (OIE) and the Codex Alimentarius Commission have established standards to prevent the entry and spread of animal diseases and zoonoses and to enhance food safety, respectively. The implementation in countries however need national legislation and its implementation by the feed businesses through risk based programmes like Hazard Analysis and Critical Control Points and their enforcement through licensing, standards of operation, auditing and management of controls. The EU feed hygiene regulation (Regulation EC No. $183 / 2005$ ) is one of the key elements to ensure that feed is produced, harvested, processed and placed on the market without compromising feed safety and specifies hygienic and traceability requirements for primary production including the feeding of animals. The EU feed marketing legislation (Regulation EC No. 767/2009) establishes conditions for placing a feed on the market to ensure traceability, information to the user for the proper use of the feed and information that ensures an adequate management during transport and storage, for example, indication of storage life, storage conditions, etc.

\section{Natural disasters and food losses}

When a crop is ready for harvest, and an adverse condition strikes (e.g. hail storm, frost and floods), the crop meant for human consumption may not be suitable for that purpose anymore. In some situations, the crops could possibly be salvaged for feeding to animals. R\&D efforts that enable to use such damaged crops as livestock feed need to be 
promoted. This conversion to feed is useful. This will not only enhance resource use efficiency but also provide some financial compensation (for the lost crop) to farmers. If crop insurance schemes exist, their state with respect to extent of damage may have to be observed, before their utilization for feed is possible. However, more commonly it will be up to the individual farmers to decide on the utilization of damaged crops. Moreover, crop farmers may not have their own livestock or face difficulties to make arrangements with livestock owners to allow for utilization as feed. In addition to grazing, conservation of the damaged crops through drying or making of silage would be an option. It appears that no actual experiences exist and to make such proposals feasible, training of farmers and policy support would be required to make them work. Facilities to preserve affected crops may not be available and under such situations farmers decide to allow damaged crops to mature which may then also lead to contaminated grains that are still used as food. The presence of hazards in the damaged crops like mycotoxins can make their use also for feeding dangerous and not advisable or this can only be done after laboratory testing. Developing countries should therefore first establish regulations to allow for safe use of affected crops for animals.

\section{Future research needs}

Some recent studies have evaluated the potential of food waste, biomass from grazing land, co-products and other humaninedible agro-products in delivering human edible protein through livestock (Schader et al., 2015; van Zanten et al., 2016), suggesting important role of livestock in converting food wastes and other human-inedible products into highly nutritious products for human nutrition. For fully exploiting the complementarities in the nexus between FLW and livestock rearing and for realizing triple wins in sustainable food systems, the future needs and actions are:

- countries to quantify food losses and waste and non-food parts from agricultural products, so as to develop strategies for their reduction and for their possible use as animal feed;

- countries to establish clear legislation to regulate the safe use of FLW and NFPC as animal feed;

- identify existing approaches for safe use of FLW and NFPC as animal feed and policies and strategies developed for its upscale;

- evaluate impact of using FLW and NFPC as animal feed on parameters such as: decrease in food-feed competition; decrease in use of resources such as land, water, energy and other resources; decrease in environmental pollution; employment generation among others;

- provide technical support to small-scale industries to utilize food wastes and losses and non-food parts as animal feed; and

- raise awareness and develop partnerships including cooperation between the food industries and feed manufacturing industries.

In addition, stakeholders from academia, feed industry to policy makers have important roles in making it possible which are discussed in the Supplementary Material.

\section{Acknowledgements}

Author thanks all the participants of the e-conference (FAO, 2015) for their thoughts and opinions, which has helped in shaping this opinion paper. Also thanks are due to Olaf Thieme and Robert VanOtterdijk for their suggestions.

The views expressed in this publication are those of the author and do not necessarily reflect the views or policies of FAO.

\section{Supplementary material}

To view supplementary material for this article, please visit https://doi.org/10.1017/S1751731117000702

\section{References}

Food and Agriculture Organization 2014. Definitional framework of food loss, Rome, Italy. Retrieved on 17 December from http://www.fao.org/fileadmin/ user_upload/save-food/PDF/FLW_Definition_and_Scope_2014.pdf.

Food and Agriculture Organization (FAO) 2015. E-conference: utilization of food loss and waste as well as non-food parts as livestock feed, FAO, Rome, Italy. Retrieved on 17 December from http://www.fao.org/save-food/news-andmultimedia/events/detail/fr/c/325893/.

Khan SH, Das KS, Amanullah NG, Dharmapuri SM and Makkar HPS 2016. Quantification, chemical composition and nutritional values of food wastes. Journal of Environment Management (in press).

Schader C, Müller A, El-Hage Scialabba N, Hecht J, Lsensee A, Erb K-H, Smith P, Makkar HPS, Klocke P, Leiber F, Schwegler P, Stolze M and Niggli U 2015. Impacts of feeding less food-competing feedstuffs to livestock on global food system sustainability. Journal of the Royal Society Interface 12, 1-12.

Van Zanten HHE, Meerburg BG, Bikker P, Herrero M and de Boer IJM 2016. Opinion paper: the role of livestock in a sustainable diet: a land use perspective. Animal 10, 547-549.

zu Ermgassen EKHJ, Phalan B, Green RE and Balmford A 2016. Reducing the land use of EU pork production: where there's $s$ a will, there's a way. Food Policy $58,35-48$. 